\title{
Severe thrombocytopenia after dasatinib treatment in a patient with Philadelphia chromosome-positive chronic myeloid leukemia
}

This article was published in the following Dove Press journal:

OncoTargets and Therapy

24 April 2015

Number of times this article has been viewed

\section{Runzhe Chen \\ Fei Wang \\ Xiaoping Zhang \\ Chong Gao \\ Baoan Chen}

Department of Hematology and Oncology (Key Department of Jiangsu Medicine), Zhongda Hospital, Medical School, Southeast University, Nanjing, Jiangsu Province, People's Republic of China
Correspondence: Baoan Chen Department of Hematology and Oncology, Zhongda Hospital, Medical School, Southeast University, Dingjiaqiao 87, Gulou District, Nanjing 210009, Jiangsu Province, People's Republic of China

Tel +86258327 2006

Fax +86258327 201।

Email cba8888@hotmail.com

\begin{abstract}
Dasatinib, a second-generation tyrosine kinase inhibitor, is used for treating patients with Philadelphia chromosome $(\mathrm{Ph})$ positive leukemia, especially for those who are resistant or intolerant to imatinib. The common adverse effects associated to its use include myelosuppression, nausea, diarrhea, and peripheral edema. This study reports a very rare case of a 60 -year-old male who suffered from severe thrombocytopenia after dasatinib administration. The platelet count did not increase even after dasatinib had been discontinued for more than 6 months. Various means had been tried, but the count of platelet did not increase, and the result was not optimistic. This is the first report of so severe thrombocytopenia after dasatinib treatment, and the pathophysiology underlying this reaction remains unknown. We hope that this case will help remind clinicians to pay more attention to the side effect of thrombocytopenia caused by dasatinib in the future.
\end{abstract}

Keywords: platelet, monoclonal antibody, hematological malignancies

\section{Introduction}

Dasatinib, a second-generation BCR-ABL tyrosine kinase inhibitor (TKI), has been approved by Food and Drug Administration in 2010 in patients with Philadelphia chromosome (Ph)-positive malignancies such as chronic myeloid leukemia (CML) and acute lymphoblastic leukemia. ${ }^{1-3}$ It is recommended at $100 \mathrm{mg}$ once daily as the starting dose in patients with chronic phase CML and at $70 \mathrm{mg}$ twice daily in patients with chronic, blastic, or accelerated phase CML who are resistant or intolerant to previous treatment, including imatinib mesylate (IM). ${ }^{1-3}$ In vitro, dasatinib has more durable complete hematologic and cytogenetic responses and more potency (325 times more active) than IM for inhibiting BCR-ABL. As a result, if the patient develops resistance or intolerance after IM administration, discontinuation of IM and switch to dasatinib could be a better choice. ${ }^{3-6}$ In the meantime, several adverse reactions have been encountered with dasatinib use as well: myelosuppression, fatigue, nausea, diarrhea, vomiting, peripheral edema, headache, and so on. Cytopenia occurs in almost all the patients treated with dasatinib; however, though not common, the rate of occurrence of grade 3/4 thrombocytopenia varies according to different clinical trials. ${ }^{7,8}$

Here, we present a patient with Ph-positive CML for 14 years who suffered from severe thrombocytopenia for more than 1 year after dasatinib treatment and in whom the platelet count did not increase even after dasatinib had been discontinued for more than 6 months. This is the first report of severe thrombocytopenia caused by dasatinib, and we hope this case will help remind clinicians to pay more attention to this side effect. 


\section{Case report}

A 60 -year-old male without previous disease was diagnosed with Ph-positive CML and had suffered from it for almost 14 years. For having no appropriate donor to do bone marrow transplantation and as he was in the chronic phase of CML, in the first 6 years, he was given oral administration of hydroxyurea continuously, and it was well tolerated. Eight years ago, with the marketing of IM, the first-generation of TKI in People's Republic of China, he began to take $400 \mathrm{mg}$ of IM per day, and his disease was well controlled.

Two years ago, because of fatigue, the patient was referred to our department. Routine blood examination revealed white blood cell count (WBC) $13.72 \times 10^{9} / \mathrm{L}$ (normal range: $4 \times 10^{9} / \mathrm{L}-10 \times 10^{9} / \mathrm{L}$ ), level of hemoglobin $11.7 \mathrm{~g} / \mathrm{dL}$ (normal range: $12-16 \mathrm{~g} / \mathrm{dL}$ ), number of platelets $410 \times 10^{9} / \mathrm{L}$ (normal range: $100 \times 10^{9} / \mathrm{L}-300 \times 10^{9} / \mathrm{L}$ ), and proportion of neutrophil normal. Bone marrow examination showed that the proportion of myelocyte and metamyelocyte was $35.2 \%$, and this indicated that the patient was still in the chronic phase of CML. IM-resistant gene was also not mutated. However, 1 year ago, routine blood examination of this patient revealed the WBC count of $162 \times 10^{9} / \mathrm{L}$, and for four consecutive months the count of WBC was always above $60 \times 10^{9} / \mathrm{L}$. The count of red blood cell and the level of hemoglobin were in accepted range. Though bone marrow examination indicated that the patient was still in the chronic phase, considering the patient's condition of disease, dasatinib was used, and the dosage of dasatinib was $100 \mathrm{mg}$ daily. After taking dasatinib, severe myelosuppression occurred in this patient, especially the platelet count, so we adjusted the dosage of dasatinib considering both the disease and the patient's count of platelet (Figure 1). On September 11, 2014, dasatinib was totally discontinued; however, the platelet count could not recover. For having no other disease except CML, the patient only took dasatinib; side effect of thrombocytopenia of dasatinib was only considered. Various means such as platelet transfusion, combined cytokines, and traditional Chinese medicine had been tried, but the number of platelets was still kept in a very stable range of $5 \times 10^{9} / \mathrm{L}-10 \times 10^{9} / \mathrm{L}$. After 3 months of dasatinib discontinuation, $\mathrm{B}$ ultrasound examination of abdomen revealed that the length of spleen increased to $13 \mathrm{~cm}$ from the previous normal size (less than $12 \mathrm{~cm}$ ). Several bone marrow examinations indicated that the percent of myelocytes and metamyelocytes was kept in about $40 \%$ and the patient was still in the chronic phase, not progressed to the accelerated phase, but the reverse transcription polymerase chain reaction (RT-PCR) showed that the positive rate of BCR-ABL increased to 388/500 from 150/500. The patient had no other special signs and symptoms except large ecchymosis caused by low platelets during the treatment in our hospital, and no other side effects related with dasatinib occurred except thrombocytopenia. The count of platelet did not have the tendency to rise, so we are afraid that the thrombocytopenia would be irreversible. What was worse, stopping dasatinib would exacerbate the CML.

\section{Discussion}

Dasatinib is generally well tolerated by patients reported in clinical trials; ${ }^{9-14}$ however, side effects also occurred in a small group of patients. Though thrombocytopenia is a very

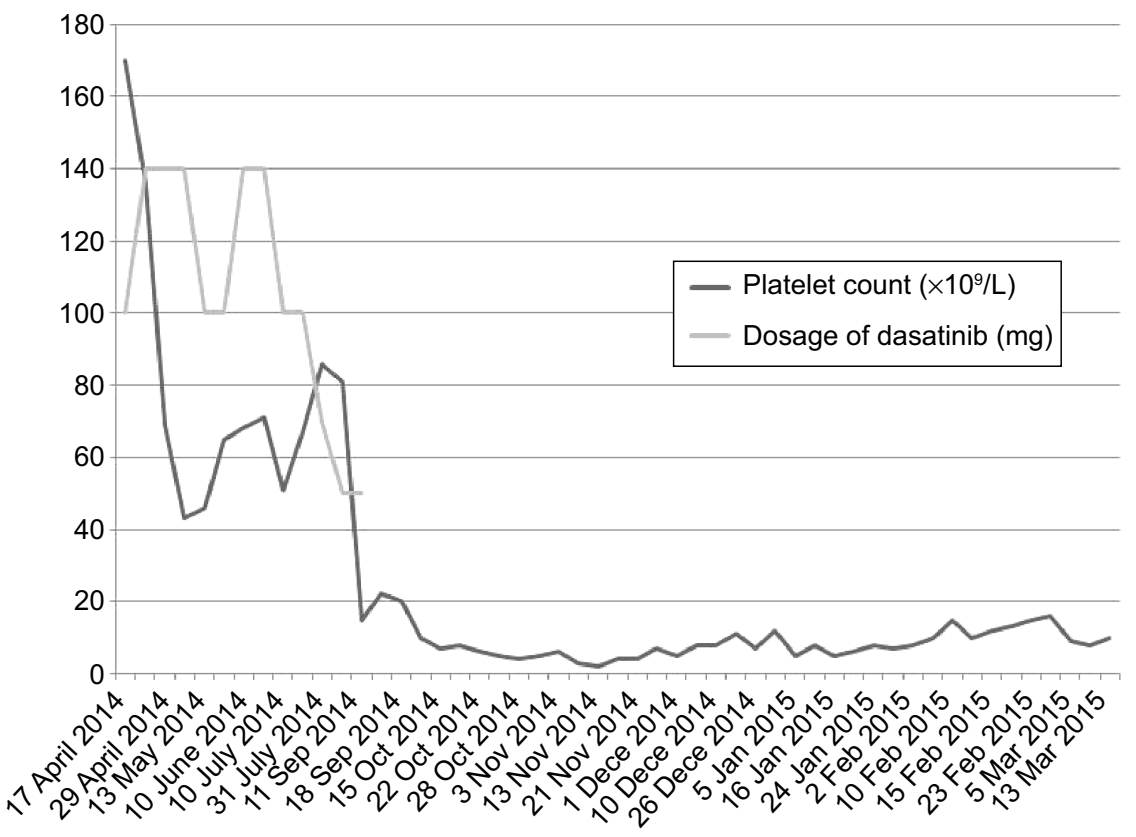

Figure I Changing trends of dasatinib dosage and platelet count from April 17, 2014 to March I3, 2015. 
common adverse effect of dasatinib, according to the results of previous clinical studies, no thrombocytopenia as severe as in our case has been reported. We present a patient with Ph-positive CML who developed thrombocytopenia during the treatment with dasatinib after ruling out other possibilities. After stopping of dasatinib for more than 6 months, the number of platelets could not recover. The mechanism and pathophysiology underlying this reaction still remained unknown. Though no standard treatment for TKI induced thrombocytopenia according to guidelines, there are some other choices after the failure of dasatinib treatment. Changing to other TKIs could be an option, but second-generation and third-generation TKIs all had the side effect of causing myelosuppression. Allogeneic hematopoietic stem cell transplantation could also be offered for those patients who presented with blast phase at diagnosis. ${ }^{11}$ For the patient we reported, because of the limitation of his age, his economic condition, and no appropriate donor, it is not suitable to do transplantation. Though we know that so severe thrombocytopenia may not occur in other patients with $\mathrm{Ph}$-positive malignancies, for reporting of this case, we just hope that this case could help guide clinicians in the future to pay more attention to the adverse effects of thrombocytopenia and also we want to ask specialists around the world to help this patient.

\section{Ethics statement}

The study was approved by the Ethics Committee of Zhongda Hospital of Southeast University. Written informed consent was also obtained from the patient for the publication of this case report.

\section{Acknowledgments}

This work was supported by the National Natural Science Foundation of China (Grant 81170492 and 81370673), National High Technology Research and Development Program 863 of People's Republic of China (Grant 2012AA022703), National Key Basic Research Program 973 of People's Republic of China (Grant 2010CB732404), Key Medical Projects of Jiangsu Province (Grant BL2014078), and Key Discipline of Jiangsu Province (2011-2015).

\section{Disclosure}

No conflict of interest in this work is reported by any author.

\section{References}

1. Heo SK, Noh EK, Yoon DJ, Jo JC, Park JH, Kim H. Dasatinib accelerates valproic acid-induced acute myeloid leukemia cell death by regulation of differentiation capacity. PLoS One. 2014;9(2):e98859.

2. Jabbour E, Lipton JH. A critical review of trials of first-line BCR-ABL inhibitor treatment in patients with newly diagnosed chronic myeloid leukemia in chronic phase. Clin Lymphoma Myeloma Leuk. 2013; 13(6):646-656.

3. Aguilera DG, Tsimberidou AM. Dasatinib in chronic myeloid leukemia: a review. Ther Clin Risk Manag. 2009;5(2):281-289.

4. Alimena G, Breccia M, Latagliata R, et al. Dasatinib in the management of lymphoid blast crisis of Philadelphia-positive chronic myeloid leukemia with multiple extra-medullary and intracranial localizations. Leuk Res. 2009;33(8):e134-e136.

5. Cortes J, Rousselot P, Kim DW, et al. Dasatinib induces complete hematologic and cytogenetic responses in patients with imatinib-resistant or -intolerant chronic myeloid leukemia in blast crisis. Blood. 2007; 109(8):3207-3213.

6. Guilhot F, Apperley J, Kim DW, et al. Dasatinib induces significant hematologic and cytogenetic responses in patients with imatinibresistant or -intolerant chronic myeloid leukemia in accelerated phase. Blood. 2007;109(10):4143-4150.

7. Lindauer M, Hochhaus A. Dasatinib. Recent Results Cancer Res (Fortschritte der Krebsforschung. Progres dans les recherches sur le cancer). 2014;201:27-65.

8. Quintas-Cardama A, De Souza Santos FP, Kantarjian H, et al. Dynamics and management of cytopenias associated with dasatinib therapy in patients with chronic myeloid leukemia in chronic phase after imatinib failure. Cancer. 2009;115(17):3935-3943.

9. Zwaan CM, Rizzari C, Mechinaud F, et al. Dasatinib in children and adolescents with relapsed or refractory leukemia: results of the CA180018 phase I dose-escalation study of the innovative therapies for children with cancer consortium. J Clin Oncol. 2013;31(19):2460-2468.

10. Keating GM, Lyseng-Williamson KA, McCormack PL, Keam SJ. Dasatinib: a guide to its use in chronic myeloid leukemia in the EU. Bio Drugs. 2013;27(3):275-279.

11. Eghtedar A, Kantarjian H, Jabbour E, et al. Outcome after failure of second generation tyrosine kinase inhibitors treatment as first-line therapy for patients with chronic myeloid leukemia. Clin Lymphoma Myeloma Leuk. 2013;13(4):477-484.

12. Krauth MT, Herndlhofer S, Schmook MT, Mitterbauer-Hohendanner G, Schlogl E, Valent P. Extensive pleural and pericardial effusion in chronic myeloid leukemia during treatment with dasatinib at $100 \mathrm{mg}$ or $50 \mathrm{mg}$ daily. Haematologica. 2011;96(1):163-166.

13. Hochhaus A, Baccarani M, Deininger M, et al. Dasatinib induces durable cytogenetic responses in patients with chronic myelogenous leukemia in chronic phase with resistance or intolerance to imatinib. Leukemia. 2008;22(6):1200-1206.

14. Cortes J, Kim DW, Raffoux E, et al. Efficacy and safety of dasatinib in imatinib-resistant or -intolerant patients with chronic myeloid leukemia in blast phase. Leukemia. 2008;22(12):2176-2183.
OncoTargets and Therapy

\section{Publish your work in this journal}

OncoTargets and Therapy is an international, peer-reviewed, open access journal focusing on the pathological basis of all cancers, potential targets for therapy and treatment protocols employed to improve the management of cancer patients. The journal also focuses on the impact of management programs and new therapeutic agents and protocols on

\section{Dovepress}

patient perspectives such as quality of life, adherence and satisfaction. The manuscript management system is completely online and includes a very quick and fair peer-review system, which is all easy to use. Visit http://www.dovepress.com/testimonials.php to read real quotes from published authors. 